\title{
Original Research Study \\ Studies on impact of Teaching the Breast Examination Skill Through Lecture, Video, Mannequin and on Real Patients, on Medical Students in Kingdom of Saudi Arabia and in India
}

\author{
Shashi Shekhar \\ ${ }^{1}$ Associate Professor, Department of General Surgery, Saraswathi Institute of Medical Sciences, Anwarpur, \\ Hapur, NCR, India
}

\begin{abstract}
Teaching of Breast Examination skill to Medical Students is a real challenge all over world as Breast is an intimate organ. Hence there is increasing effort to find alternative to teaching on real patients for confidant development of communicative and Palpative skull.

In ethically prohibitive cultures (ie. Kingdom of Saudi Arabia) Didactic Lecture followed by Video demonstration plays significant role in ethically prohibitive cultures in teaching of Breast Examination Communication skill; where as Didactic Lecture followed by Video demonstration and Mannequin Demonstration and Practice plays significant role in ethically in teaching of Breast Examination Palpation skill.

In ethically less prohibitive cultures (ie. India) Didactic Lecture followed Bed side demonstration of Breast examination on real patient plays significant in Communication skill ; where as Didactic Lecture followed by Video and Bed side demonstration of Breast examination on real patient and Practice plays significant role in Breast Palpation skill.
\end{abstract}

Key words: Ethical Challenges, Cultural issues, Clinical setting, Female Breast Examination, Medical Student,Health Educator.

\section{Introduction}

Cancer breast may present with lump, changes in the skin ie. dimpling, indurations, oedema-peau d'orange, and changes in nipples ie. nipple retraction, ulceration, discharge. Identifying these is an important clinical skill issue. ${ }^{1,2}$

The standards of acquisition of clinical skills among medical students is on profound decline. Many students

\section{Corresponding Author:}

\section{Shashi Shekhar}

Laparoscopic Surgeon \& Andrologist

Men's Health Clinic, Pinnacle Tower B-305, Indirapuram-Ahinsa Khand 2, Ghaziabad -201014,

UP-NCR.; Email: drdrshashishekhar@gmail.com ; TEL: +91-9989691292 learn intimate physical examination imperfectly and often only finally after passing MBBS, in the setting of internship.

The reasons for decline identified include staff's heavy duties, reduced funding, reduced hospital stay and increasing day care procedures. ${ }^{3}$ Mannequin based simulators use is increasing for clinical teaching. ${ }^{4}$ Dedicated and structured clinical skills training is an important factor for bed side clinical training. ${ }^{5}$

$11 \%$ of women complaining of a breast lump and $4 \%$ of women with any breast complaint were found to have a malignancy. ${ }^{6,7} 34 \%$ of women with invasive breast cancer initially presented with a palpable lesion. $13 \%$ of the women with a palpable breast mass who were found to have invasive cancer had a normal mammogram within the previous year. The sensitivity of mammography with a self-reported breast lump as $87.3 \%$. ${ }^{8}$ Approximately 
$13 \%$ of clinically evident breast cancers may be missed by mammography imaging. ${ }^{9}, 10$

Teaching techniques in relation to Clinical Skill of Breast Examination from ancient till date includes:

1. Under anaesthesia- Intimate examination skills were taught on patients under anaesthesia and often without taking consent,

2. Real patients- are asked for consent to participate in the teaching of intimate examination skills to medical students.

3. Didactic Lecture- Instructions on clinical techniques through lectures.

4. Booklet, Brochure, Videos - Used during teaching.

5. Mannequin- Demonstration on mannequins; for close approximation of reality.

6. Actor Patient.

8. Peer Physical examination.

9. Teaching Associates as Simulated Patients..

Country Specific Teaching techniques used to develop bed side skill of medical students:

1. Real Patients: UK-70\%; Australia-90\%; US$25 \%$,

2. Teaching Associates: Canada-38\%; UK-5\%; Australia-45\%; US-75\%,

3. Actor Patients: Canada-25\%; UK-5\%\%; Australia22\%-\%; US-25\%\%,

4. Mannequins: Canada- $90 \%$; UK- $95 \%$; Australia-92\%; US-60\%,

\section{Aims of the Study}

1. To study impact of teaching communication skills in Breast Examination through Lecture, Video, Mannequin and Real Patients on Medical students. Detection of Breast Lump in Kingdom of Saudi Arabia and in India.

2. To study impact of teaching palpation skill in Breast Examination through Lecture, Video, Mannequin and Real Patients on Medical students. Detection of Breast Lump in Kingdom of Saudi Arabia and in India.

\section{Materials and Method}

Material: The 57 medical students in Kingdom of Saudi Arabia and 58 Students in India in their clinical posting years were evaluated for Communication Skill and Palpation Skill for Breast Examination with an aim to detect breast masses.In KSA at Salmanbin Abdelaziz University College of Medicine, Al Kharj, Kingdom of Saudi Arabia Breast Examination skill were taught to 32 and 25 medical students of 2012-13 and 2013-14 batch and their skills of Communication and Palpation were gauzed through OSCE. In INDIA at Saraswathi Institute of Medical Sciences, Anwarpur, Hapur-NCR, India Breast Examination skill were taught to 28 and 30 medical students group of 2017-18 and 2018-19 batch and their skills of Communication and Palpation were gauzed through Clinical Exam VIVA.

\section{Method}

1, Scoring Method for Brest Exam Clinical Skill :

a. In Kingdom of Saudi Arabia-Scoring through OSCE on Mannequin.: (a). Breast Case scenario: Ms. Fatima is a 52-year-old female, who came to the clinic because she noticed a breast lump while taking a shower last week. Vital signs: BP 135/80 P 70/min R 14/min Temp $99.5^{\circ} \mathrm{F}\left(37.5^{\circ} \mathrm{C}\right)$; (b). Student tasks are to: 1 . Obtain a focused history, 2. Perform a relevant physical examination, 3. Discuss initial diagnostic impression and workup plan with the patient, 4. After leaving the room, complete patient note on the form provided; (c).

\section{Evaluators tasks are: Scoring on OSCE}

\section{b. In India -through Viva on Long case of Breast}

Lump : (a). Real female patient with lump in breast-A real female patient with lump in breast was provided for examination to the medical student.; (b). Students task was to: 1.Introduction, 2.Seeking Consent for private part (Breast) Examination, 3.Ensure privacy and presence of female attendant; 4.Obtaining a focussed history 5.Performing a relevant physical examination 6 . Discuss initial diagnostic impression and workup plan with the patient. 7.After leaving the room, complete patient note on the form provided; (c). Evaluators tasks are to: Ask relevant Question, Observe skill of Communication and palpation and give Scoring. 
2. Components based Evaluation of Breast Examination Clinical skill

a. Communication skill includes History Taking (HT) skill: (a). Properly introduced himself to patient, Took patients consent for physical examination, (b). Established and maintained rapport with patient;

(c).Washed his/her hands or prepped with antiseptic, used appropriate draping techniques. (d). Performed the exam in an organized fashion; Made the patient feel comfortable, used good non-verbal skills, closed the exam in an appropriate manner

b. Inspection-Palpation skill includes: (a). Inspection skill: With patient sitting, inspected both breasts from front and sides. Asked patient (a). to put arms overhead (b).to put arms on her waist and press elbows forward. (c) To lean forward with arms out in front ; (b). Palpation Skill : With patient sitting:(a). palpated the cervical, supraclavicular and axillary lymph node (b). performed bimanual palpation of the breast; With patient supine: Asked patient to put arms overhead, Performed complete palpation of the breast with the flat part of the fingers, Performed palpation of the axillary tail, Gently palpated and expressed nipples.

\section{Observations of Research Study}

A. Communication Skill for Breast Examination:

(A1). After Didactic lecture followed by Video demonstration and Manikin Examination OSCE Scores were as follows:

\section{1, In KSA OSCE Scores were as follows:}

a.The OSCE score among 32 Students of 2012-13 session were: Not done

b. The OSCE score distribution among 25 students of 2013-14 batches scored: $>60$ to $70 \%$-01 students, $>70$ to $80 \%$ by 19 students and $>80$ to $80 \%$ by 05 students.

(A2). After Didactic lecture followed by Video demonstration and Real Patient Clinical Examination VIVA Scores were as follows:

\section{In INDIA -VIVA Scores were as follows:}

a.The VIVA score distribution among 28 Students of 2017-18 sessions were: $>60$ to $70 \%-00$ students, $>70$ to $80 \%$ by 18 students and $>80$ to $80 \%$ by 07 students.

a. The VIVA score distribution among 30 students of 2018-19 batches scored: $>60$ to $70 \%-16$ students, $>70$ to $80 \%$ by 14 students, $>80-90 \%-09 ;>90-100 \%-04$ students.

\begin{tabular}{|c|c|c|c|c|c|c|c|c|}
\hline SCORE \% & $\begin{array}{l}2012- \\
\text { KSA }\end{array}$ & & $\begin{array}{l}201 \\
\mathrm{KS}\end{array}$ & & $\begin{array}{l}2017- \\
\text { INDIA }\end{array}$ & & $\begin{array}{l}\text { 2018- } \\
\text { INDI }\end{array}$ & \\
\hline STUDENT & 32 & $\begin{array}{l}\text { OSCE \% } \\
\text { SCORE }\end{array}$ & 25 & OSCE \% SCORE & 28 & $\begin{array}{l}\text { CLINICAL } \\
\text { EXAM \% } \\
\text { SCORE }\end{array}$ & 30 & $\begin{array}{l}\text { CLINICAL } \\
\text { EXAM \% } \\
\text { SCORE }\end{array}$ \\
\hline $\begin{array}{l}\text { DIDACTIC } \\
\text { LECTURE } \\
\text { (DL) }\end{array}$ & 32 & $\begin{array}{l}>60-70 \%-17 \\
>70-80 \%-13 \\
>80-90 \%-02 \\
>90-100 \%-00\end{array}$ & 25 & $\begin{array}{l}>60-70 \%-16 \\
>70-80 \%-09 \\
>80-90 \%-00 \\
>90-100 \%-00\end{array}$ & 28 & $\begin{array}{l}>60-70 \%-15 \\
>70-80 \%-12 \\
>80-90 \%-01 \\
>90-100 \%-00\end{array}$ & 30 & $\begin{array}{l}>60-70 \%-16 \\
>70-80 \%-14 \\
>80-90 \%-00 \\
>90-100 \%-00\end{array}$ \\
\hline $\begin{array}{l}\mathrm{DL}+\mathrm{VIDEO} \\
\& \mathrm{OSCE} \%\end{array}$ & XXX & XXXXXZXXX & 25 & $\begin{array}{l}>60-70 \%-01 \\
>70-80 \%-19 \\
>80-90 \%-05 \\
>90-100 \%-00\end{array}$ & $\mathrm{XXX}$ & XXXXXZXXX & $\mathrm{XXX}$ & XXXXXX \\
\hline
\end{tabular}

B. Palpation Skill for Breast Examination: 
(B1). After Didactic Lecture OSCE / VIVA Scores were as follows:

1. In KSA After Didactic Lecture Palpation Skill OSCE Scores were as follows:

a. The OSCE score distribution among 32 Students of $2012-13$ session were : $>50-60 \%$ by 18 students, $>60$ to $70 \%-10$ students, $>70$ to $80 \%$ by 04 students.

b. The OSCE score distribution among 25 students of 2013-14 batch scored :> 50 to $60 \%$ by 20 students, $>60$ to $70 \%-05$ students.

\section{In INDIA Palpation Skill VIVA Scores were} as follows:

a. The VIVA score distribution among 28 Students of 2017-18 sessions were: $>60$ to $70 \%-15$ students, $>70$ to $80 \%$ by 12 students and $>80$ to $80 \%$ by 01 students.

b. The VIVA score distribution among 30 students of 2018-19 batches scored: $>60$ to $70 \%-16$ students, $>70$ to $80 \%$ by 14 students, $>80-90 \%-00 ;>90-100 \%-00$ students.

(B2), After Didactic lecture followed by Video demonstration and Mannikin Palpation the Palpation

Skill OSCE/VIVA Scores were as follows

1.In KSA: Palpation Skill OSCE Scores were as follows

a. The OSCE score distribution among 32 Students of 2012-13 session were : $>50-60 \%$ by 00 students, $>60$ to $70 \%-00$ students, $>70$ to $80 \%$ by 03 students. $>80$ 90\%-23 students ; $>90-100 \%-06$ students.

b. The OSCE score distribution among 25 students of $2013-14$ batch scored : $>50$ to $60 \%$ by 00 students, $>60$ to $70 \%-00$ students. $>70-80 \%-13$ students, $>80$ 90\%-11;>90-100\%- 01 student.

\section{In INDIA Palpation Skill VIVA Scores were as follows:}

After Didactic lecture followed by Video demonstration \& Practice on Real bed side patient the Palpation Skill VIVA Scores were as follows:

a. The VIVA score distribution among 32 Students of $2012-13$ session were $>70$ to $80 \%$ by 18 students, $>80$ to $90 \%$ by 07 students and $>90$ to $100 \%$ by 03 students.;

b. The VIVA score distribution among 30 students of 2013-14 batch scored $>60-70 \%-03$ Students , $>70$ to $80 \%$ by 14 students, $>80$ to $90 \%$ by 09 students and $>90$ to $100 \%$ by 04 students.

\section{Discussion}

Teaching related challenges in teaching female breast examination skill are: Real challenge in medical education is to provide training in physical examination skills.; The teaching of the sensitive examination of female breast is a Challenging part of undergraduate medical curriculum.; It remains difficult to ensure adequate quantity and quality of training.; Intimate examination(physical examination of female breast) is generally taught Intentionally or Opportunistically using a number of strategies: Didactic Lectures or Demonstrations, Individual practice on inanimate simulators-manikins, Individual practice with simulated patients/trainers, Individual practice on patients in a clinical setting with varying degrees of supervision ; Teaching of intimate physical exam may be sporadic and opportunistic.; Some patient attendants may become violent when their female partner is medically attended by male doctors.

1. In Kingdom of Saudi Arabia (KSA) Communication skill score among medical students improved by Didactic Lecture followed by Video demonstration by $10 \%$ in 25 students and by $20 \%$ in 03 Students, when compared to didactic lecture alone.

2. In INDIA Communication skill score among medical students improved by Didactic Lecture followed by Video demonstration and Mannequin practice by $15 \%$ in 24 students and by $20 \%$ in 01 Students, when compared to didactic lecture alone-

\section{In Kingdom of Saudi Arabia (KSA) Palpation} skill score among medical students improved by Didactic Lecture followed by Mannequin Demonstration and Practice by $10 \%$ in 18 students of 2012-13 batch and 16 students of 2013-14 batch; and by $20 \%$ in 07 students of 2012-13 batch and 06 students of 2013-14 batch, when compared to didactic lecture alone.

4. In INDIA Palpation skill score among medical 
students improved by Didactic Lecture followed by Demonstration and

practice on real patients By $10 \%$ in 18 students of 2012-13 batch and 13 students of 2013-14 batch; and by $20 \%$ in 10 students of 2012-13 batch and 12 students of 2013-14 batch, when compared to didactic lecture alone-

\section{Conclusion}

a. Teaching of Breast Examination skill to Medical Students is a real challenge all over world as Breast is an intimate organ. Hence there is increasing effort to find alternative to teaching on real patients for confidant development of communication and Palpation skull.

\section{b. In ethically prohibitive cultures (ie. Kingdom of Saudi Arabia)}

Didactic Lecture followed by Video demonstration plays significant role in ethically prohibitive cultures in teaching of Breast Examination Communication skill, its positive impact is between $10 \%$ on $89 \%$ Medicos and $20 \%$ on $11 \%$ Medical Students of 2012-13 batch of Medical Students in Kingdom of Saudi Arabia.

Where as Didactic Lecture followed by Video demonstration and Mannequin Demonstration and Practice plays significant role in ethically in teaching of Breast Examination Palpation skill. Thus, its positive impact is $10 \%$ on $72 \%$ of $2012-13$ and $72 \%$ of $2012-13$ batch of Medical Students in Kingdom of Saudi Arabia.

\section{India)}

c. In ethically less prohibitive cultures (ie.

Didactic Lecture followed Bed side demonstration of Breast examination on real patient plays significant in Breast Examination Communication skill; Thus, its positive impact is $15 \%$ on $96 \%$ of $2017-18$ batch and $90 \%$ on $2018-19$ batch Medico's in India.

Where as Didactic Lecture followed by Video and Bed side demonstration of Breast examination on real patient and Practice plays significant role in Breast Examination Palpation skill.

Thus, its positive impact is $10 \%$ in $64,2 \%$ Medicos of $2017-18$ and $52 \%$ Medicos of 2018-19 batch. The Positive impact is $20 \%$ on remaining $35.8 \%$ of $2017-18$ batch and on 48\% of 2018-19 batch Medicos in India.

Conflict of Interest: No conflict of interest.

Source of Funding: Self-funding

Ethical Clearance: The ethics review was not considered in this study to require approval. Informed consent was obtained prior to the SP training. The participation was voluntary. All participants gave written informed consent.

\section{References}

(1). Phil Halligan.: Caring for patients of Islamic denomination: critical care nurses' experiences in Saudi Arabia : Journal of Clinical Nursing, 2006 December : Vol.15, issue 12: 1565-1573

(2). Selena A. Hunter, Alice McLachlan, Takayoshi Ikeda, Michael J. Harrison, Duncan C. Galletly: Teaching of the sensitive examinations: An international survey Open Journal of Preventive Medicine( 4) 2014: 41-49

(3). Awad Mohamed Ahmed : Role of clinical skills centers in maintaining and promoting clinical teaching. Sudanese Journal of Public Health: April 2008, Vol.3 (2) : 97-103 Available from: https:// www.researchgate.net/publication/237748643

(4). Epps C., White M.L., Tofil N. :Mannequin Based Simulators. In: Levine A.I., DeMaria S., Schwartz A.D., Sim A.J. (eds) The Comprehensive Textbook of Healthcare Simulation. Springer, New York, NY, 2013:721

(5). Patsy Stark \& F. Fortune: Career issues for learners, Teaching Clinical Skills in Developing Countries: Are Clinical Skills Centres the Answer? Research Gate - Education for Health, Vol. 16, No. 3, November 2003: 298 - 306 Available from: https://www.researchgate.net/publication/8903978 [Accessed Mar 12 2020].

(6). Barton MB, Elmore JG, Fletcher SW.: Breast symptoms among women enrolled in a health maintenance organization: frequency, evaluation, and outcome. Ann Intern Med. 1999 April 20;130(8):651-657.

(7). Haakinson DJ, Stucky CH, Dueck AC, et al. The Clinical Breast Exam: A Skill that Should Not Be Abandoned . Am J Surg. 2010;200(6):712-717. 
(8). Barlow WE, Lehman CD, Zheng Y, et al. Performance of diagnostic mammography for women with signs or symptoms of breast cancer. J Natl Cancer Inst. 2002 Aug 7;94(15):1151-1159.

(9). Teresa Bryan, and Erin Snyder,: The Clinical Breast Exam: A Skill that Should Not Be Abandoned ; J
Gen Intern Med. 2013 May; 28(5): 719-722.

(10). Kann, P E; Lane, D S: Breast cancer screening knowledge and skills of students upon entering and exiting a medical school. [Article] Academic Medicine. 1998 Aug;73(8):904-906. 